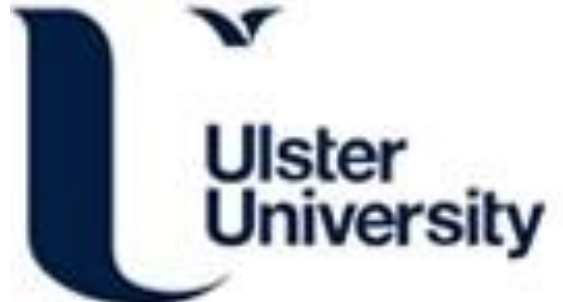

\section{Antibiofilm Effects of Macrolide Loaded Microneedle Patches: Prospects in Healing Infected Wounds}

Arshad, M. S., Zahra, A. T., Zafar, S., Zaman, H., Akhtar, A., Ayaz, M. M., Kucuk, I., Maniruzzaman, M., Chang, M-W., \& Ahmad, Z. (2021). Antibiofilm Effects of Macrolide Loaded Microneedle Patches: Prospects in Healing Infected Wounds. Pharmaceutical Research, 38(1), 165-177. https://doi.org/10.1007/s11095-021-02995-0

Link to publication record in Ulster University Research Portal

\author{
Published in: \\ Pharmaceutical Research
}

Publication Status:

Published (in print/issue): 03/02/2021

DOI:

10.1007/s11095-021-02995-0

\section{Document Version}

Author Accepted version

\section{General rights}

Copyright for the publications made accessible via Ulster University's Research Portal is retained by the author(s) and / or other copyright owners and it is a condition of accessing these publications that users recognise and abide by the legal requirements associated with these rights.

\section{Take down policy}

The Research Portal is Ulster University's institutional repository that provides access to Ulster's research outputs. Every effort has been made to ensure that content in the Research Portal does not infringe any person's rights, or applicable UK laws. If you discover content in the Research Portal that you believe breaches copyright or violates any law, please contact pure-support@ulster.ac.uk. 


\section{Antibiofilm Effects of Macrolide Loaded Microneedle Patches: Prospects in Healing Infected Wounds}

Muhammad Sohail Arshad ${ }^{1}$, Aleema Tehreem Zahra ${ }^{1}$, Saman Zafar ${ }^{1}$, Hussain Zaman ${ }^{2}$, Ambreen Akhtar ${ }^{2}$, Muhammad Mazhar Ayaz ${ }^{3}$, Israfil Kucuk ${ }^{4}$, Mohammad Maniruzzaman ${ }^{5}$, Ming-Wei Chang ${ }^{6}$, Zeeshan Ahmad ${ }^{2}$

${ }^{1}$ Faculty of Pharmacy, Bahauddin Zakariya University, Multan, Pakistan

${ }^{2}$ Leicester School of Pharmacy, De Montfort University, Leicester, United Kingdom

${ }^{3}$ Cholistan University of Veterinary and animal Sciences, Bahawalpur, Pakistan

${ }^{4}$ Gebze Technical University, Gebze, Turkey

${ }^{5}$ College of Pharmacy, The University of Texas at Austin, Austin, Texas, USA

${ }^{6}$ Nanotechnology and Integrated Bioengineering Centre, University of Ulster, Newtownabbey, Northern Ireland, UK 


\section{Graphical abstract}

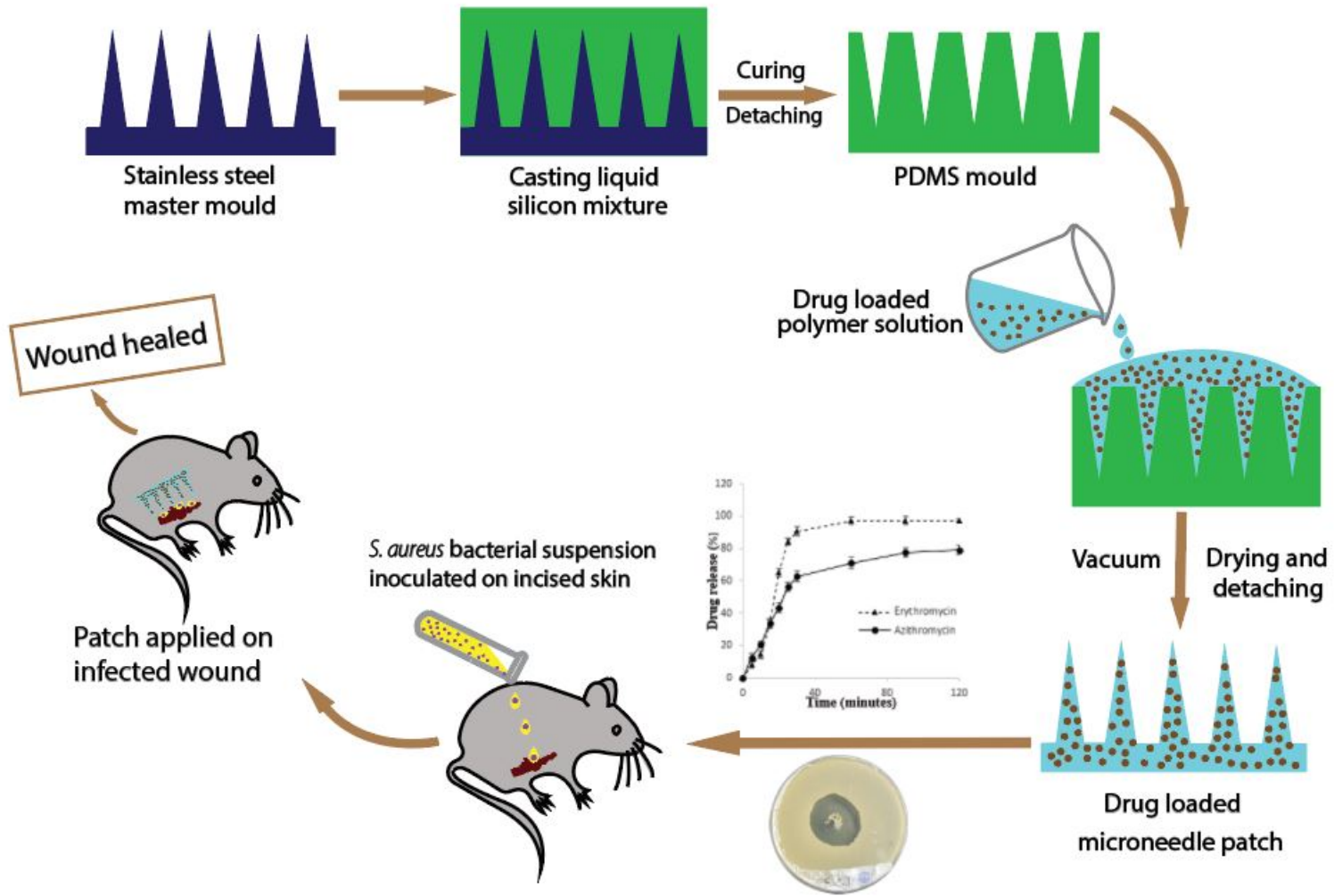




\begin{abstract}
Aim: The aim of this study was to fabricate polymeric microneedles, loaded with macrolides (erythromycin, azithromycin), using hyaluronic acid and polyvinyl pyrollidone.

Methods: These microneedles were fabricated using a vacuum micromolding technique. The integrity of the microneedle patches was studied by recording their morphologic features, folding endurance, swelling and micro-piercing. Physicochemical characteristics were studied by differential scanning calorimetry, thermogravimetric analysis and fourier transform infrared spectroscopy. In-vitro drug release, antibiofilm and effect of microneedle patch on wound healing were also studied to confirm the efficacy of the formulations.

Results: Formulated patches displayed acceptable folding endurance $(>100)$ and uniform distribution of microneedles $(10 \times 10)$ that can penetrate parafilm. Differential scanning calorimetry results depict a decrease in the crystallinity of macrolides following their incorporation in to a polymer matrix. Percentage release of azithromycin and erythromycin from the polymeric patch formulations (over 30 minutes) was $90 \%$ and $63 \%$ respectively. Broadly, the zone of bacterial growth inhibition follows the same order for Staphylococcus aureus, Escherichia coli and Salmonella enterica. After 5 days of treatment with azithromycin patches, the wound healing was complete and skin structure (e.g. hair follicles and dermis) was regenerated.
\end{abstract}

Conclusion: It was concluded that azithromycin loaded microneedle patches can be used to treat biofilms in the infected wounds.

Keywords: Microneedles; Macrolide; Azithromycin; Erythromycin; Biofilm; Transdermal 


\section{Introduction}

The skin is the human body's first line of defence which prevents the invasion of microbes; regulates body temperature; maintains fluids and electrolytes balance $(1,2)$. Following a skin injury, the integrity of this natural barrier is compromised, allowing microbial penetration to the exposed subcutaneous tissues, which serves as a nutritious medium for their colonization. Microbial proliferation, if untreated, results in the development of biofilms which consequently leads to an impaired or delayed wound healing. Biofilms are mono or polymicrobic in nature and form a dynamic heterogenous structure, which resists both antimicrobial therapy and immune response of the human body $(3,4)$.

Penetration of antibacterial agents to the infected wounds through conventional dosage forms such as creams, lotions, gels and dressings are restricted due to superficial and necrotic tissue, which serve as a barrier (5). A novel delivery system such as a microneedle (MN) patch, can possibly improve antibacterial agent penetration, promote wound healing and overcome issues related to conventional antibacterial therapy. A MN patch is comprised of an array of micronsized projections and can administer a loaded drug topically or transdermally without stimulating nociceptors (6-9). Polymeric MN patches are being extensively used for wound management applications due to their biocompatible, inert, biodegradable and less toxic nature $(10,11)$.

Hyaluronic acid (HA), a water swellable, non-sulfated macromolecule (molecular weight $10^{4}$ $10^{7}$ Daltons), exhibits biodegradable, non-antigenic and biocompatible properties which makes it a potential candidate as a drug carrier. HA, a highly hydrophilic polymer, forms a loose-fitted hydrated matrix by absorbing water up to $\sim 1000$ times its volume. It plays an important role in wound healing as it modulates inflammatory responses, accelerates keratinocytes proliferation/migration and angiogenesis $(12,13)$. Polyvinyl pyrollidone (PVP) is an inert, nonirritant, biocompatible, biodegradable, temperature resistant and non-ionic film forming polymer. (14-17). PVP has been extensively used in the pharmaceutical field for drug delivery purposes/formulations with proven biosafety. It has been reported in the literature that capillaries of glomeruli allow low molecular weight PVP (MW <25000) to pass through ultrafilter. While, the post glomerular capillaries permit 110,000 and 650000 to pass through. Furthermore, disposition of PVP through monocyte/macrophage system has also been reported (18). Sorbitol, a fruit sugar, is an efficient plasticizer that acts by forming hydrogen bonds with its hydroxyl groups and other components of polymeric matrix (19). 
Common microbes isolated from wounds include $S$. aureus (prevalent isolate), E. coli and $S$. enterica. Antibiofilm activity of macrolides is proven. Local administration of macrolides at a wound site is desirable as it reduces the chances of drug resistance by ensuring optimal concentration of antibacterial agent to microbes $(5,20-22)$. Topical formulations of macrolides are rarely available owing to its macrocyclic lactone induced slow permeation through the skin. If developed, topical delivery of macrolides through MNs can be an ideal solution as it is expected to benefit the management of infected wounds whilst promoting antibacterial effects.

The aim of the present study was to fabricate erythromycin and azithromycin loaded patches using a HA/PVP polymer blend as a MN base and sorbitol as a plasticizer. Prepared MN patches were evaluated for in-vitro drug release profile, antimicrobial and antibiofilm activity.

\section{Materials and methods}

\subsection{Materials}

Sodium hyaluronate was purchased from REB technology, Zheijiang, China. Polyvinylpyrrolidone (PVP, average molecular weight 40,000), D-sorbitol, sodium hydroxide and nutrient agar were purchased from Sigma Aldrich, Steinheim, Germany. Erythromycin was kindly donated by Ferozsons Laboratories Ltd., Lahore, Pakistan. Azithromycin dihydrate was gifted by Saffron Pharmaceutical Company, Faisalabad, Pakistan. Potassium hydrogen phthalate, sulfuric acid, hydrochloric acid $(\mathrm{HCl})$ and methanol were purchased from Merck, Darmstadt, Germany. Distilled water was prepared, in house, using all glass apparatus (Department of Pharmaceutics, Bahauddin Zakariya University Multan, Pakistan).

\subsection{Preparation of microneedles}

Polydimethylsiloxane (PDMS) molds $(10 \times 10$ needles $)$ of discrete needle sizes were prepared using a method presented earlier by the authors (23). Briefly, stainless steel master molds of known microneedle geometries were manufactured by conventional machining methods including grinding, electro-discharge process and electropolishing of the microneedles. In the next stage, a liquid silicon-based molding solution was prepared by mixing dow corning sylgard 184 silicon and hardener at a ratio 10:1. This mixture was transferred to master molds and heated at $80^{\circ} \mathrm{C}$ for $\sim 1$ hour. Cured polydimethylsiloxane (PDMS) MN molds of complementary shape were separated from the master molds.

Formulations containing varying concentrations of HA $(1-3 \% \mathrm{w} / \mathrm{v})$, PVP $(20-40 \% \mathrm{w} / \mathrm{v})$ and D-sorbitol (10\% dry weight of total polymeric mass), were prepared by dissolving the 
polymers in distilled water at $\sim 50^{\circ} \mathrm{C}$ whilst stirring continuously for $1 \mathrm{~h}$, followed by the addition of sugar. These solutions were maintained at ambient conditions $\left(25 \pm 2^{\circ} \mathrm{C}\right)$ and centrifuged at $3000 \mathrm{rpm}$ for 5 minutes in order to remove trapped air bubbles. The contents of blank formulations were poured over PDMS molds, under vacuum, and incubated at $25^{\circ} \mathrm{C}$ for $48 \mathrm{~h}$ allowing solidification of the polymer mass into MN patches (24). Finally, blank MN patches were detached from the mold by gently heating this assembly at $40^{\circ} \mathrm{C}$.

For fabrication of drug loaded MN patches, methanolic solution of drugs (erythromycin or azithromycin) were added dropwise to an existing polymer solution with continuous stirring (the drug content was $10 \%$ w.r.t dry polymer weight). The solution was then degassed through centrifuging and poured over PDMS molds using the same method described for blank formulations.

\subsection{Physical examination}

\subsubsection{Optical imaging}

Prepared patches were examined by recording photographic images using a Samsung HD camera WB150F Seoul, South Korea. MN patches were also visualized under an optical microscope (Labomed, Los Angeles, USA) with a 4x lens.

\subsubsection{Uniformity of thickness and width}

The dimensions of prepared patches were measured in terms of their thickness, width etc. Each sample was measured at five different positions using a digital caliper (Lufen 02-067-4, Zhejiang, China). The uniformity of the size was ascertained by recording the values of these parameters in different samples $(\mathrm{n}=5)$.

\subsubsection{Folding endurance}

Prepared patches $(n=5)$ were folded repeatedly at the same position until they cracked, or their integrity was lost.

\subsubsection{Swelling study}

A dry patch with known mass $\left(\mathrm{m}_{\mathrm{o}}\right)$ was immersed in distilled water. The swollen patch was removed at pre-determined time intervals, surface water was cleaned using adsorbant paper and the mass of the imbibed sample $\left(\mathrm{m}_{\mathrm{s}}\right)$ was recorded. Following each measurement, the sample was re-immersed and the procedure was repeated until a constant mass was obtained. Percent (\%) swelling was measured using equation given below;

$$
\% \text { Swelling }=\frac{(m s-m o)}{m o} \times 100
$$




\subsection{Scanning electron microscopy}

Microneedle patches were examined by field emission scanning electron microscope (FESEM, Zeiss, Gemini SEM 300, Oberkochen, Germany) to study their surface morphology and dimensions of MNs. The samples were sputter coated with gold solution ( $\sim 10 \mathrm{~nm}$ thickness) and electron micrographs were recorded at $5-15 \mathrm{kv}$.

\subsection{Differential scanning calorimetry}

Thermal stability of formulations and their constituents i.e. polymers, plasticizer, drugs and patches, were assessed using a differential scanning calorimeter (NETZSCH DSC 404C, Selb, Germany). Small sample sizes (10-20mg) were transferred to an alumina pan and heated from $25^{\circ} \mathrm{C}$ to $350^{\circ} \mathrm{C}$, at a rate of $10^{\circ} \mathrm{C} /$ minute, under the dry nitrogen gas purge $(50 \mathrm{ml} / \mathrm{min})$. As the temperature increased, the enthalpic changes in the samples were recorded. The instrument was calibrated for temperature and heat flow using Nickle as a standard under the dry nitrogen gas purge.

\subsection{Thermogravimetric analysis}

The physical stability of the finished product and components e.g. polymers, drugs and sorbitol, were studied using a thermogravimetric analyzer (Mettler Toledo, Ohio, USA). A sample, approximately $5-15 \mathrm{mg}$, was heated from $25^{\circ} \mathrm{C}$ to $550^{\circ} \mathrm{C}$ at a heating rate of $10^{\circ} \mathrm{C} /$ minute under an oxygen flow rate of $20 \mathrm{ml} / \mathrm{min}$. The samples were analyzed for mass loss following an increase in temperature.

\subsection{In-vitro insertion study}

Skin simulant parafilm was used to observe the insertion ability of microprojections at the patches. A patch was applied to the parafilm (thickness $120-130 \mu \mathrm{m}$, dimension $4 \mathrm{x} 4 \mathrm{~cm}$ ) using thumb pressure for 30 seconds. The $\mathrm{MN}$ treated parafilm was examined under a microscope (4x lens) for the presence of microsized imprints of microstructures $(25,26)$.

\subsection{In-vitro drug release study}

In-vitro release study of erythromycin was performed by adapting spectrophotometry based analytical methods reported in literature (27). Briefly, a stock solution of erythromycin $(200 \mu \mathrm{g} / \mathrm{ml})$ was prepared using distilled water and methanol mixture (25:1). Different dilutions $(25,50,75,100,125$ and $150 \mu \mathrm{g} / \mathrm{ml})$ were prepared from a stock solution, $1 \mathrm{ml} 27 \mathrm{~N}$ sulfuric 
acid was added in each dilution and absorbance was recorded at $\lambda_{\max } 485 \mathrm{~nm}$. The absorbance data was modelled using a linear regression equation and goodness of fit was determined in terms of correlation coefficient $\left(\mathrm{R}^{2}\right)$. For in-vitro erythromycin release study, a $\mathrm{MN}$ patch formulation was stirred $(100 \mathrm{rpm})$ in a dissolution medium $(50 \mathrm{ml}$, acidified phosphate buffer solution $\mathrm{pH} 5.4$ ) at $37^{\circ} \mathrm{C}$ using a magnetic stirrer (Stuart, Staffordshire, UK). Aliquots (3ml) were drawn at pre-defined intervals $(5,10,15,20,25,30,60,90$ and 120 minutes $)$ and the volume of the dissolution chamber was re-established, using phosphate buffer solution $\mathrm{pH} 5.4$ (blank medium), in order to maintain sink conditions. Samples were further diluted with blank dissolution medium and absorbance at $\lambda$ max was recorded. The amount of drug released from the patches, was determined using the equation $(x=y-b / m)$.

On the other hand, for azithromycin, a stock solution of $(50 \mu \mathrm{g} / \mathrm{ml})$ was initially prepared in $0.1 \mathrm{M} \mathrm{HCl}$. Different dilutions of known strength $(10,15,20,25,30,35,40$ and $45 \mu \mathrm{g} / \mathrm{ml})$ were prepared using stock solution and the absorbance was recorded at $\lambda_{\max } 275 \mathrm{~nm}$ (28). A calibration curve was constructed by plotting the absorbance as a function of azithromycin concentration. A linear regression equation was applied to fit the absorbance data and goodness of fit was determined in terms of correlation coefficient $\left(\mathrm{R}^{2}\right)$. In-vitro release of azithromycin was studied using a dissolution medium containing phosphate buffer $(\mathrm{pH} 5.4)$ and $\mathrm{HCl}(0.1 \mathrm{M})$ at volume ratio 50:1. In vitro drug release was studied by following the above stated method.

\subsection{Antimicrobial assay}

Different bacterial strains namely, Salmonella enterica (S. enterica) [ATCC 35664], Eacherichia coli (E. coli) [ATCC 25922] and Staphylococcus aureus (S. aureus) [ATCC 23235] were used in this study. The stock cultures of these bacteria were preserved in suitable agar slants and maintained at $4^{\circ} \mathrm{C}$. Bacterial suspensions $\left(\sim 10^{5} \mathrm{CFU} / \mathrm{ml}\right)$ were prepared from the stock cultures and poured in to petri dishes (diameter $\sim 55 \mathrm{~mm}$ ), containing autoclaved solidified nutrient agar medium (prepared by dissolving $2.3 \mathrm{~g}$ of nutrient agar in $100 \mathrm{ml}$ distilled water with concomitant heating and agitation). This working culture was incubated at $25 \pm 1{ }^{\circ} \mathrm{C}$ for 24 hours in order to achieve an optimal bacterial cell density.

The working cultures were treated with a known strength of drug $(1 \mathrm{mg} / \mathrm{ml}$ drug solution in methanol for standard and patch containing equivalent drug concentration in case of test sample) following the formation of a well in the petri dish. Zones of bacterial inhibition in the petri dishes were measured and results were compared with standard. 


\subsection{Antibiofilm activity}

Animal studies were performed according to the protocols approved by the BZU ethical committee vide letter number 11/PEC/2019. Male albino rats with an average weight (200$300 \mathrm{~g}$ ) were housed at $25 \pm 2{ }^{\circ} \mathrm{C}$ under a $12 \mathrm{~h} \mathrm{D} / \mathrm{L}$ cycle with free access to water and food. Rats $(\mathrm{N}=15)$ were divided in three groups $(\mathrm{A}, \mathrm{B}$ and $\mathrm{C})$. Hairs from the abdominal region of the rats were removed using calcium thioglycolate chemical depilatory. An incision $(\sim 2 \mathrm{~cm})$ was made using a sterile surgical blade under anesthesia, induced by ketamine $(40 \mathrm{mg} / \mathrm{kg}$ administered by IP route). S. aureus bacterial suspension $\left(10^{5} \mathrm{CFU} / \mathrm{ml}\right)$ was inoculated on incised skin and animals were housed for 3 days in order to develop bacterial biofilm. A sample was taken from infected skin using an inoculation loop, cultured in autoclaved nutrient agar, incubated at $25 \pm 1^{\circ} \mathrm{C}$ for $24 \mathrm{~h}$. the colonies of infecting cells were fixed to a microscopic slide and cells were stained using the gram staining method. Bacterial cells were observed under a microscope $(10 \mathrm{x}$ lens) to confirm the identity of the infecting bacterial cells and results were compared with uninfected skin sample.

Once the biofilms were established, the first group (A) was treated with blank MN patches (blank), whilst the second (B) and third (C) groups were treated with erythromycin and azithromycin loaded patches respectively (labelled as test B \& C). Treatment was given for five days, treated skin was observed for the effect on biofilm and wound healing.

\subsection{Histological examination}

Rats from each group were sacrificed on the sixth day and skin tissue samples were collected using a sterile blade. Excised skin samples were fixed in $37 \%$ formaldehyde and labelled to maintain their identity. Skin specimens were cut into thin slices (thickness $\sim 1-2 \mu \mathrm{m}$ ), fixed on a glass slide and stained with hematoxylin \& eosin staining. Excised tissues were studied, using an optical microscope (10x lens), for reduction/eradication of bacterial biofilm as well as anatomical changes in the skin following the insertion of MNs.

\section{Results and discussion}

\subsection{Physicochemical evaluation}

The physical attributes of the prepared patches are described in table 1. MN patches prepared without a plasticizer were brittle; formulations derived from low concentrations of polymer HA/PVP blend (HA 1\% and PVP 20\% w/v) were fragile with an imperfect microstructure. Likewise, the MN patches prepared from higher concentrations of HA and PVP (HA 3\%, PVP $40 \% \mathrm{w} / \mathrm{v}$ ) exhibited non-uniform sized microstructures, as viscous polymeric solution could 
not fill microcavities under the processing conditions. Polymeric blend of HA and PVP at concentrations $1.5-2.5 \%$ and $25-35 \% \mathrm{w} / \mathrm{v}$ formed patches with desirable structural features and folding endurance. The optimized formulation containing HA $1.5 \% \mathrm{w} / \mathrm{v}$, PVP $25 \% \mathrm{w} / \mathrm{v}$ and sorbitol 10\% (w.r.t dry weight of HA/PVP) was further investigated in the next phase of the study.

Table 1: Physicochemical evaluation of patches

\begin{tabular}{|c|c|c|c|c|c|}
\hline $\begin{array}{l}\text { Formulation title } \\
\text { and composition }\end{array}$ & $\begin{array}{c}\text { Patch } \\
\text { Thickness } \\
\text { (mm) }\end{array}$ & $\begin{array}{l}\text { Patch } \\
\text { Width } \\
(\mathrm{mm})\end{array}$ & $\begin{array}{c}\text { Folding } \\
\text { endurance }\end{array}$ & $\begin{array}{c}\text { Swelling } \\
(\%)\end{array}$ & $\begin{array}{c}\text { MN } \\
\text { morphology } \\
\text { / integrity }\end{array}$ \\
\hline $\begin{array}{c}\mathbf{F}_{1}(\text { HA } 3 \%, \\
\text { sorbitol } 10 \%)\end{array}$ & $0.86 \pm 0.013$ & $7.87 \pm 0.12$ & 50 & $75.7 \pm 0.77$ & + \\
\hline $\begin{array}{l}\mathbf{F}_{2}(\mathrm{PVP} 40 \%, \\
\text { Sorbitol } 10 \%)\end{array}$ & $0.88 \pm 0.015$ & $7.80 \pm 0.14$ & 48 & $77.6 \pm 0.97$ & + \\
\hline $\begin{array}{c}\mathbf{F}_{3}(\text { HA } 1 \%, \text { PVP } \\
20 \% \text { Sorbitol } 10 \\
\%)\end{array}$ & $0.87 \pm 0.011$ & $7.83 \pm 0.10$ & 65 & $93.4 \pm 0.80$ & ++ \\
\hline $\begin{array}{c}\mathbf{F}_{4}(\mathrm{HA} 1 \%, \text { PVP } \\
25 \% \text { Sorbitol } 10 \\
\%)\end{array}$ & $0.86 \pm 0.012$ & $8.00 \pm 0.13$ & 85 & $91.7 \pm 0.71$ & +++ \\
\hline $\begin{array}{c}\text { F }_{5}(\text { HA } 1.5 \%, \\
\text { PVP } 20 \% \\
\text { Sorbitol } 10 \%)\end{array}$ & $0.88 \pm 0.010$ & $7.86 \pm 0.12$ & 100 & $90.2 \pm 0.86$ & ++++ \\
\hline $\begin{array}{c}\text { F }_{6}(\text { HA } 1.5 \%, \\
\text { PVP } 25 \% \\
\text { Sorbitol } 10 \%)\end{array}$ & $0.87 \pm 0.014$ & $7.97 \pm 0.13$ & 120 & $100.0 \pm 0.93$ & +++++ \\
\hline $\begin{array}{c}\mathbf{F}_{7}(\text { HA } 1.5 \%, \\
\text { PVP } 25 \% \\
\text { Sorbitol } 10 \%, \\
\text { Azithromycin } 10 \\
\%)\end{array}$ & $0.87 \pm 0.014$ & $7.90 \pm 0.12$ & 115 & $94.0 \pm 0.92$ & +++++ \\
\hline
\end{tabular}




\begin{tabular}{|c|l|l|l|l|l|}
\hline F $_{\mathbf{8}}$ (HA 1.5 \%, & $0.87 \pm 0.014$ & $7.96 \pm 0.10$ & 120 & $93.4 \pm 0.71$ & +++++ \\
PVP 25\%, & & & & & \\
Sorbitol 10\%, & & & & & \\
Erythromycin 10 & & & & & \\
$\%)$ & & & & & \\
\hline
\end{tabular}

Symbols: +++++ very good; ++++ good; +++ average; ++ poor; + Very poor

Prepared patches were transparent white in color, with an average thickness of $0.87 \pm 0.014 \mathrm{~mm}$ (figure 1). A uniform distribution of microprojections was evident from photographic images. Patches were folded more than 100 times without any cracks, thus, proving their integrity under the use conditions. Patches also demonstrated $>90 \%$ swelling within 15 minutes, suggesting a prompt water uptake which, in turn, may warrant an efficient drug release following skin application.
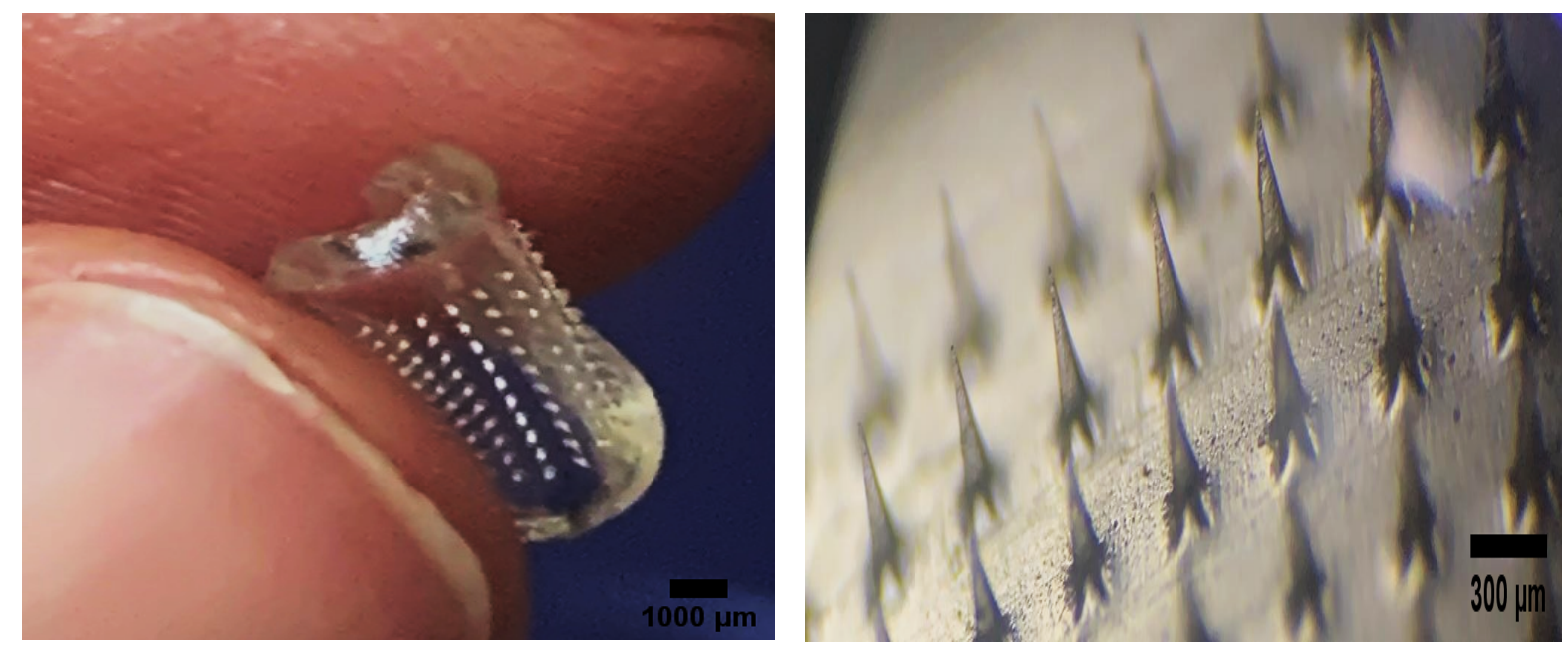

Fig. 1. (Left) photographic image (right) optical image of patch

\subsection{Scanning electron microscopy}

SEM photomicrographs of prepared patches showed MNs as square pyramids with pointed tips and smooth surfaces. Microprojections were evenly spaced with uniform distribution (figure 2 ). Furthermore, the height of microneedle was observed to be within $\sim 80 \%$ of the mould specification. The surface of the patch appears smooth following inclusion of the drug, suggesting an intimate mixing of the drug and excipients results in reduced crystallinity of the macrolide particles. This may prompt improved aqueous solubility of antibiotics. 

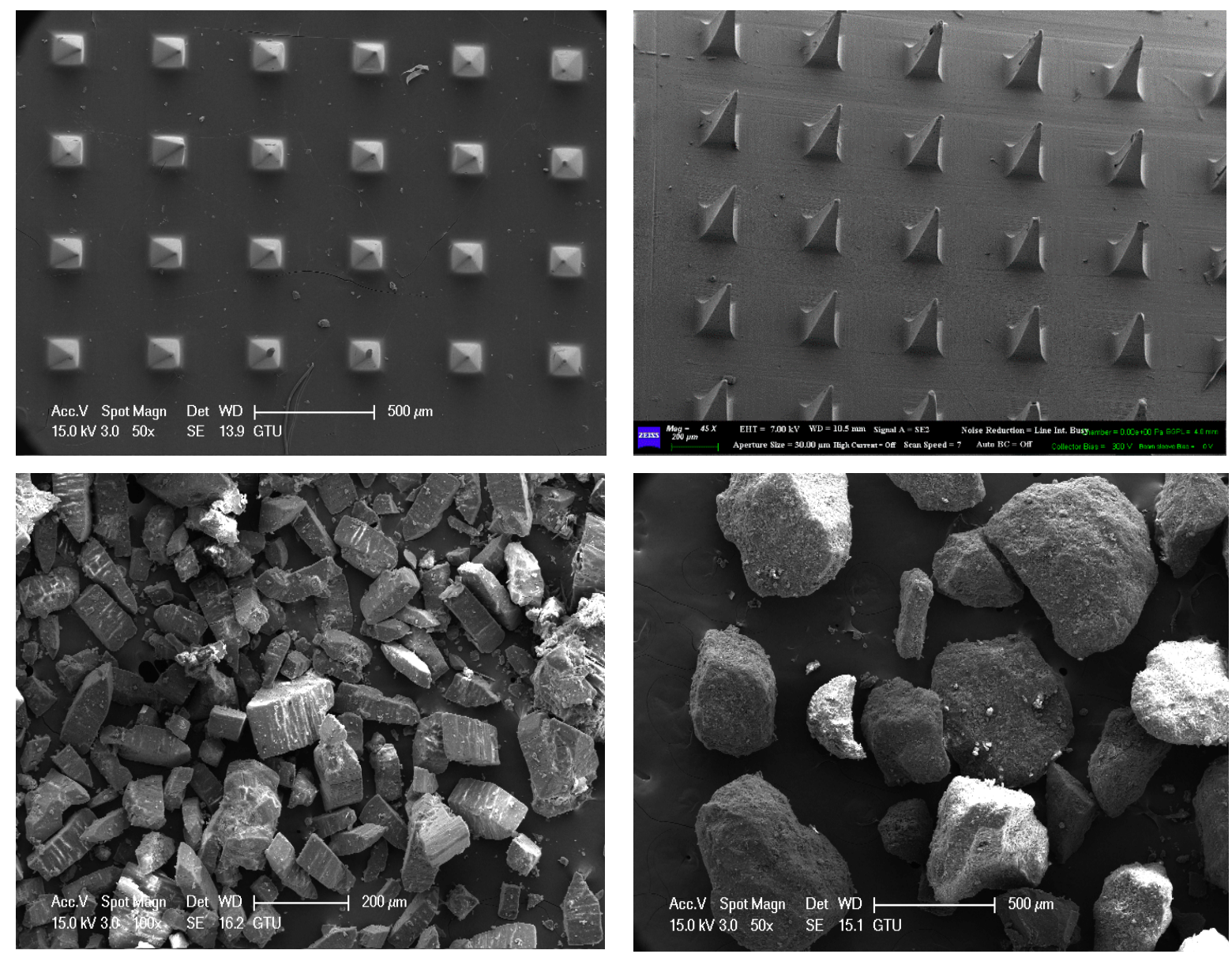

Fig. 2. SEM image of azithromycin loaded (top left), erythromycin loaded (top right) MN patch, azithromycin (bottom left) and erythromycin (bottom right) powder

\subsection{Differential scanning calorimetry}

DSC thermograms of prepared MN patches and formulation components are described in figure 3. DSC thermogram of HA showed two peaks; an endotherm at $\sim 94^{\circ} \mathrm{C}$ suggesting a dehydration process, in comparison, a sharp exotherm recorded at $238^{\circ} \mathrm{C}$ represented decomposition of HA resulting in formation of carbonized residue (29).
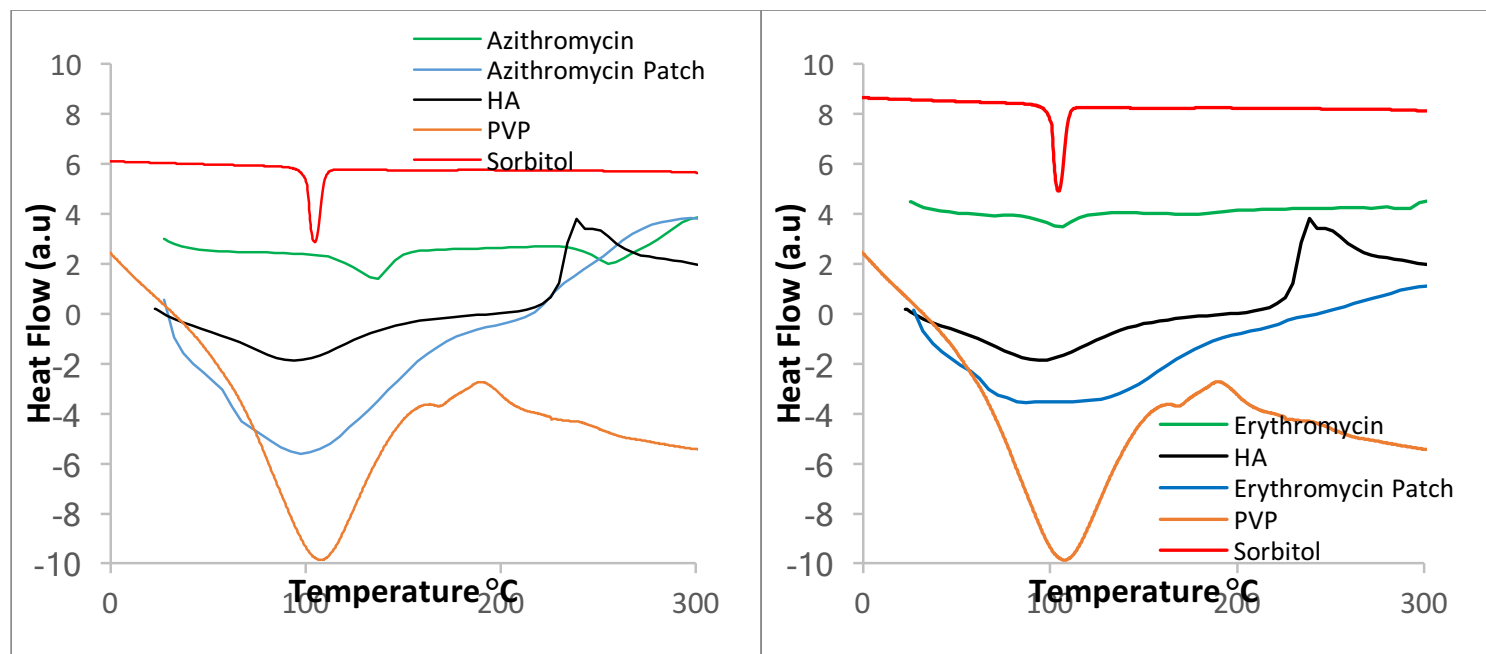
Fig. 3 . DSC thermograms of pure components and azithromycin (left), erythromycin (right) loaded patch

DSC thermogram of PVP depicts a broad endothermic peak at $108^{\circ} \mathrm{C}$ representing its glass transition temperature. As PVP is predominately amorphous in nature, an endothermic peak describing its melting at $170^{\circ} \mathrm{C}$ (onset at $\sim 165^{\circ} \mathrm{C}$ ) is less prominent (30).

Thermal scan of sorbitol powder displayed a sharp endothermic peak at $104.5^{\circ} \mathrm{C}$, with an onset at $100^{\circ} \mathrm{C}$ and end set at $110^{\circ} \mathrm{C}$, indicating the melting of crystalline mass. After $280^{\circ} \mathrm{C}$, decomposition of sorbitol was recorded.

DSC scan of pure erythromycin exhibited a strong endotherm at $107^{\circ} \mathrm{C}$, with an onset and end set at $85^{\circ} \mathrm{C}$ and $133^{\circ} \mathrm{C}$, indicating the removal of water of crystallization. Whereas, a broad endotherm over a temperature range $146-196^{\circ} \mathrm{C}$ was attributed to the melting of erythromycin (31). Drug decomposition was observed after $280^{\circ} \mathrm{C}$. DSC thermogram of erythromycin patch showed an endotherm from $72-82^{\circ} \mathrm{C}$, depicting a glass transition temperature of the polymer blend. A distinctive melting peak for the drug was absent, suggesting that erythromycin has transformed into an amorphous state in the prepared patch. At higher temperatures $\left(\sim 300^{\circ} \mathrm{C}\right)$ degradation of organic matter was observed.

Thermogram of azithromycin records a sharp endothermic peak at $137^{\circ} \mathrm{C}$ (onset at $111^{\circ} \mathrm{C}$ ) indicating the melting of azithromycin crystals. After $230^{\circ} \mathrm{C}$, decomposition of the drug was observed (32). Thermogram of azithromycin patch showed a broad endotherm over a temperature range of $67-77^{\circ} \mathrm{C}$, representing a composite glass transition of the blended mass. No melting peak of sorbitol was recorded in the calorimetric scan, suggesting that the plasticizer has transformed into an amorphous state during formulation. Likewise, the absence of a characteristic melting peak of azithromycin suggests that the drug has witnessed a physical transition, from crystalline to amorphous form in the MN patch. An exothermic peak was recorded at $\sim 300^{\circ} \mathrm{C}$ which refers to the thermal decomposition of the patch.

\subsection{Thermogravimetric analysis}

TGA thermograms of a prepared patch and pure components are shown in figure 4. Mass loss in pure HA powder was recorded in three phases. In the first phase a mass loss $\left(\sim 13 \%\right.$ at $\left.200^{\circ} \mathrm{C}\right)$ was observed due to the evaporation of free and structurally bound water. The second phase $\left(215-275^{\circ} \mathrm{C}\right)$ exhibits rapid degradation of $\mathrm{HA}$; a total of $50 \%$ mass loss was recorded. The third phase was slow with a further $15 \%$ mass loss, over a temperature range of $275-550^{\circ} \mathrm{C}$, suggested the increasing decomposition of HA. 

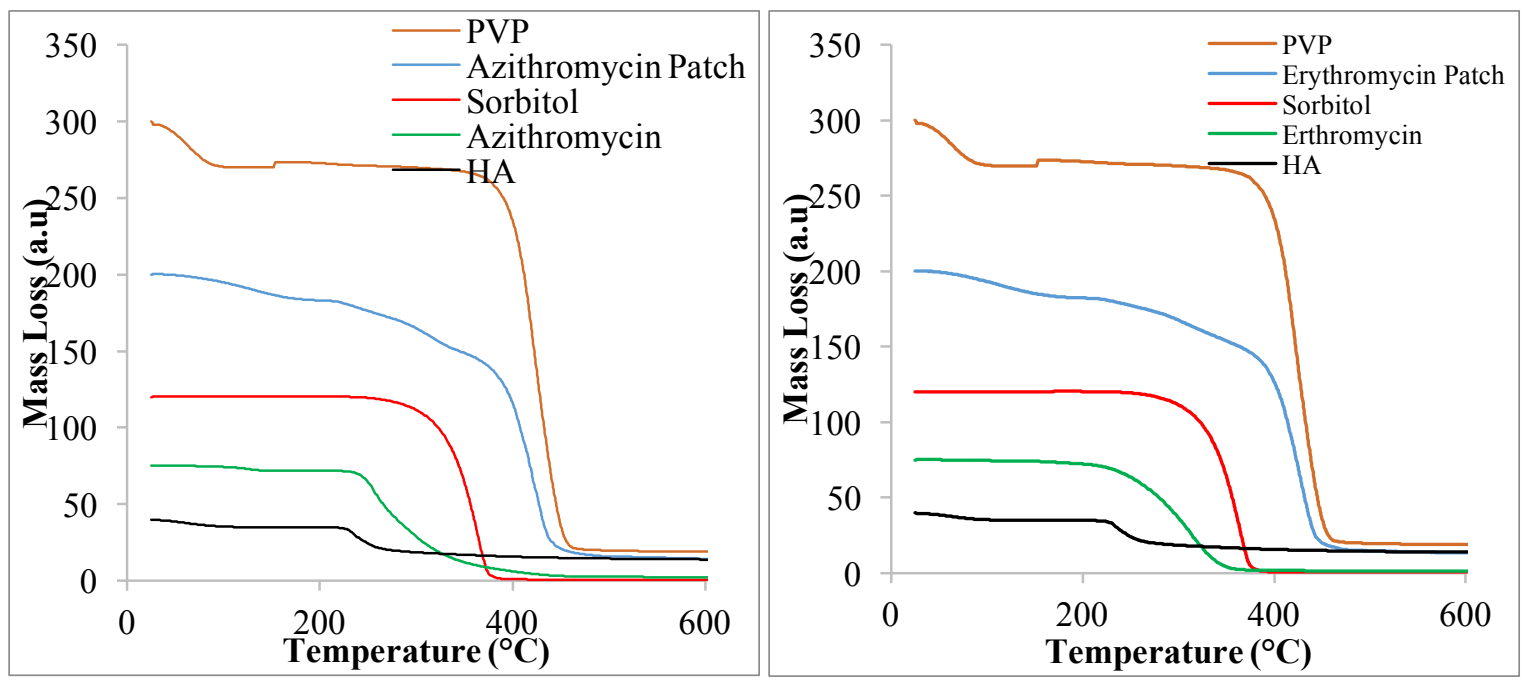

Fig. 4. TGA thermograms of pure components and azithromycin (left), erythromycin (right) loaded patch

Thermogravimetric profile of PVP manifest approximately a $12 \%$ mass loss up to $100^{\circ} \mathrm{C}$ due to removal of adsorbed water. An additional $\sim 80 \%$ mass loss was recorded as the temperature was increased from 370 to $550^{\circ} \mathrm{C}$. This rapid loss in the product mass was attributed to thermal degradation of PVP due to oxidation (33).

Thermogram of sorbitol did not register measurable weight loss until $230^{\circ} \mathrm{C}$. With a further increase in temperature $\left(233-375^{\circ} \mathrm{C}\right)$ the sugar sample displayed a mass loss of approximately $97 \%$ due to its thermal decomposition.

Thermogram of Azithromycin depicts a mass loss of $4 \%$ over a temperature range of $90-140^{\circ} \mathrm{C}$. This is due, primarily, to the removal of adsorbed water. Following a temperature elevation from 220 to $370^{\circ} \mathrm{C}$ a mass loss of around $22 \%$ was observed due to the decomposition of organic mass. Another rapid mass loss $(50 \%)$ was observed over a temperature range of $377-$ $445^{\circ} \mathrm{C}$ as a result of the oxidation of the residual mass.

Erythromycin TGA thermogram displayed a mass loss of only $4 \%$ due to water removal at $120^{\circ} \mathrm{C}$, this suggests good stability of the drug at higher temperatures. A significantly larger mass loss $(\sim 50 \%)$ was observed over a temperature range $203-296^{\circ} \mathrm{C}$, due to pyrolysis of the organic mass.

The thermogram of prepared patches exhibits a close similarity. This is because both samples comprise of PVP ( $\sim 90 \%$ of the dry mass). As the temperature increased to a value of $200^{\circ} \mathrm{C}$, around $10 \%$ mass of the patch was lost due to the removal of adsorbed water. Another $15 \%$ mass loss was recorded for erythromycin at $355^{\circ} \mathrm{C}$. Similar changes were also observed in the Azithromycin loaded samples, but only once the temperature had surpassed $335^{\circ} \mathrm{C}$. An additional $65 \%$ mass loss was recorded following elevation of sample temperature from 377 to 
$450^{\circ} \mathrm{C}$, suggesting the increase in degradation due to pyrolysis of the materials. In conclusion, the results confirm thermal stability of the formulation and its components over the use conditions.

\subsection{In-vitro insertion study}

Microscopic photographs of MN treated parafilm, manifested projections of microstructures onto model skin. Images showed that MNs of size $\geq 300 \mu \mathrm{m}$ were engraved prominently on parafilm. Clear imprints of microprojections on parafilm suggests that prepared MNs would penetrate across skin layers, thereby, efficiently delivering antibiotics to the microrganisms residing in the skin layers (Figure 6).
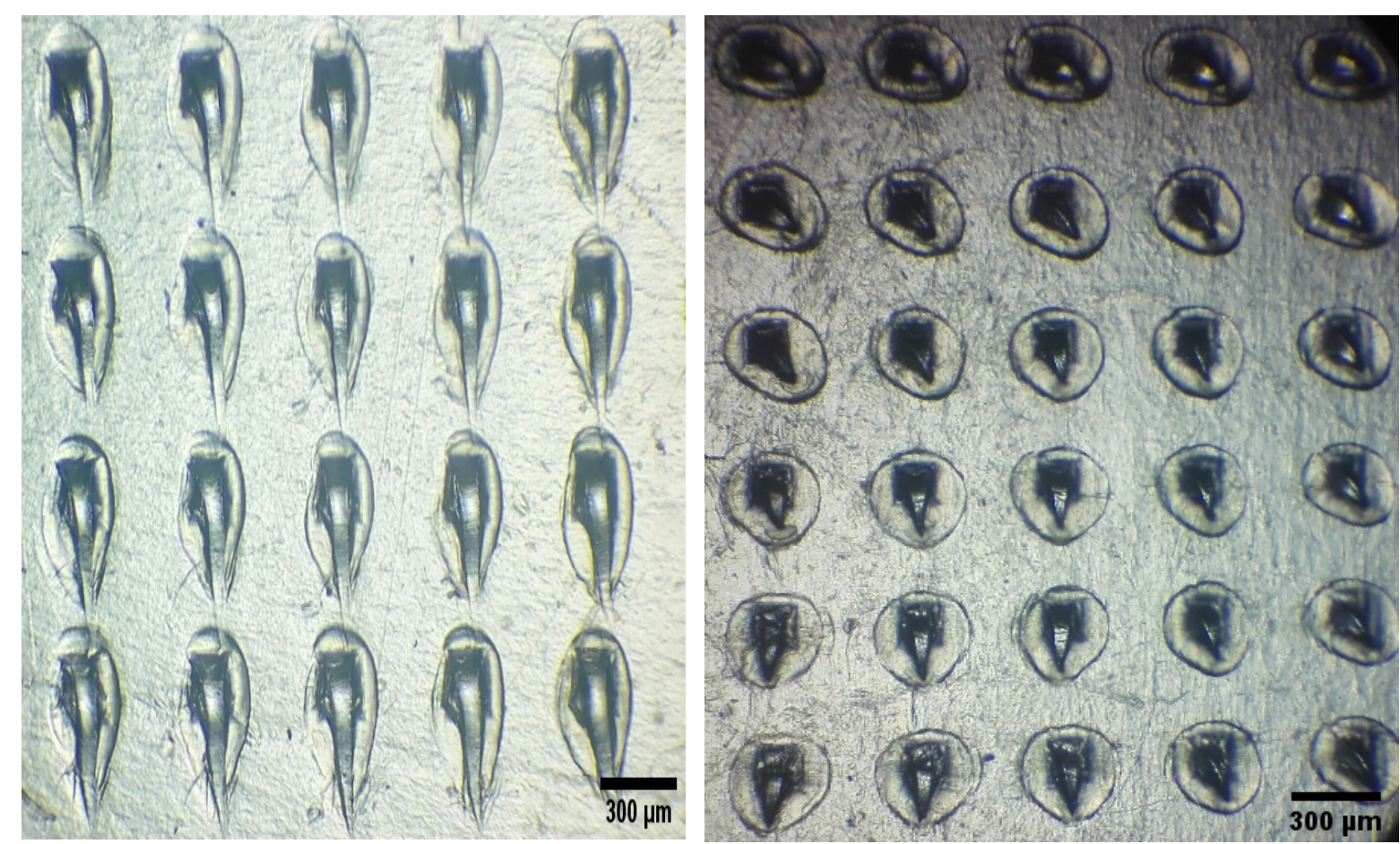

Fig. 5. Microscopic image of azithromycin patch (left) and erythromycin patch (right) treated parafilm (insertion force approximately $17 \mathrm{~N}$ )

\subsection{In-vitro drug release study}

Calibration curves of erythromycin and azithromycin are described in figure 7. Developed methods were validated by two performance parameters; limit of detection (LOD) and limit of quantification (LOQ). LOD and LOQ for erythromycin were 17.53 and $53.11 \mu \mathrm{g} / \mathrm{ml}$, whereas azithromycin had LOD and LOQ values of 1.70 and $5.16 \mu \mathrm{g} / \mathrm{ml}$. The correlation coefficient $\left(\mathrm{R}^{2}\right)$ for erythromycin and azithromycin was 0.9882 and 0.9982 , respectively, indicating that the analytical methods can reliably quantify drug concentration in the test formulations. 
In-vitro drug release profile of azithromycin, from MN patch formulation, appears biphasic; the first phase of drug release (0-30 minutes) displays a $\sim 63 \%$ drug release with a gradient of 2.13. In comparison, the second phase (30-120 minute) depicts a $16 \%$ drug release with a gradient of 0.13 . A significantly higher gradient of the initial phase can be explained by the fact that water-soluble polymer (PVP) has limited release retardant properties. Nevertheless, a prompt delivery of appropriate and tolerable concentration of azithromycin at the site of injury is desirable for effective microbial killing.

The in-vitro release of erythromycin from the MN patch formulation follows an initial time lag of 10 minutes, during which only a $15 \%$ drug release was observed. Afterwards a prompt $70 \%$ of the drug was released in 15 minutes with a gradient of 5.08. Release profile of both erythromycin and azithromycin followed first order kinetics model with small modifications.
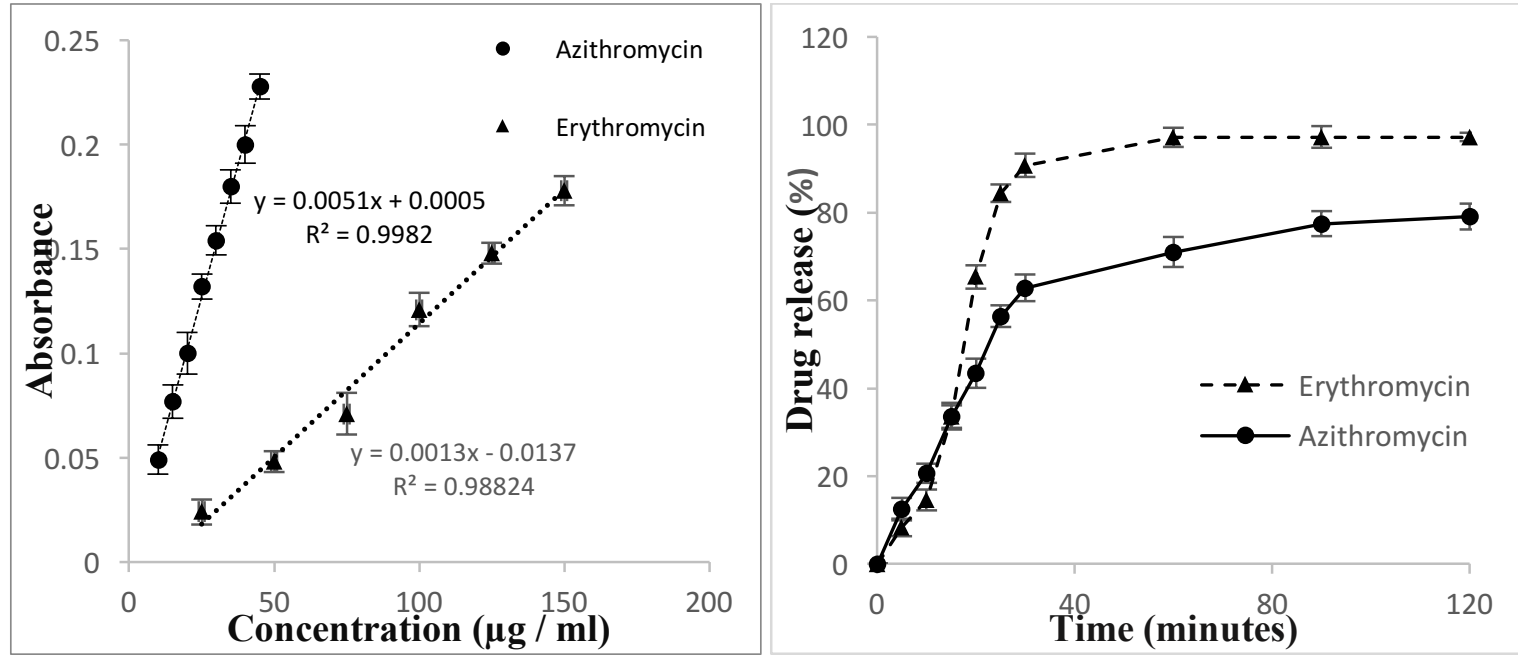

Fig. 6. Calibration curve of azithromycin and erythromycin (left), in-vitro release profile of azithromycin and erythromycin (right)

\subsection{Antimicrobial assay}

Antibacterial efficacy of erythromycin and azithromycin patches was assessed by measuring zone of inhibition in the bacterial culture of $S$. aureus, E. coli, and $S$. enterica (figure 8). The average inhibitory zones recorded, after the application of a blank $\mathrm{MN}$ patch, were $71.26 \pm 11.8$, $81.65 \pm 15.2$ and $88.1 \pm 17.6 \mathrm{~mm}^{2}$ against $E$. coli, S. aureus and $S$. enterica, respectively. The zone of inhibitions recorded from the azithromycin solution $(1 \mathrm{mg} / \mathrm{ml})$ were significantly bigger than blank formulation i.e. $712.64 \pm 17.96,1143.11 \pm 59.4$ and $1499.79 \pm 54.8 \mathrm{~mm}^{2}$ against $E$. coli, $S$. aureus and S. enterica, respectively. Mean inhibitory zones ascribed to the application of the azithromycin loaded patch against the selected bacterial strains were $\sim 90 \%$ of the values obtained with standard antibiotic solution. 
The zone of inhibitions recorded from the erythromycin solution $(1 \mathrm{mg} / \mathrm{ml})$ were significantly bigger than blank formulation i.e. $675.29 \pm 27.2,912.27 \pm 41$ and $983.73 \pm 18.2 \mathrm{~mm}^{2}$ against $E$. coli, S. aureus and S. enterica, respectively. Zones of inhibition registered from the samples treated with erythromycin loaded patch against $\mathrm{E}$ coli and $\mathrm{S}$ aureus were $>80 \%$ of standard erythromycin solution.

The results of data analysis using one-way ANOVA revealed a significant $(\mathrm{P}$ value $<0.05)$ increase in the zone of inhibition following the application of formulations and standard antibiotic solution. Furthermore, an insignificant result ( $\mathrm{P}$ value $>0.05$ ) of comparison of mean zone of inhibition from formulated patches and standard antibiotic solutions, suggested that the former is effective and useful for the eradication of infections.
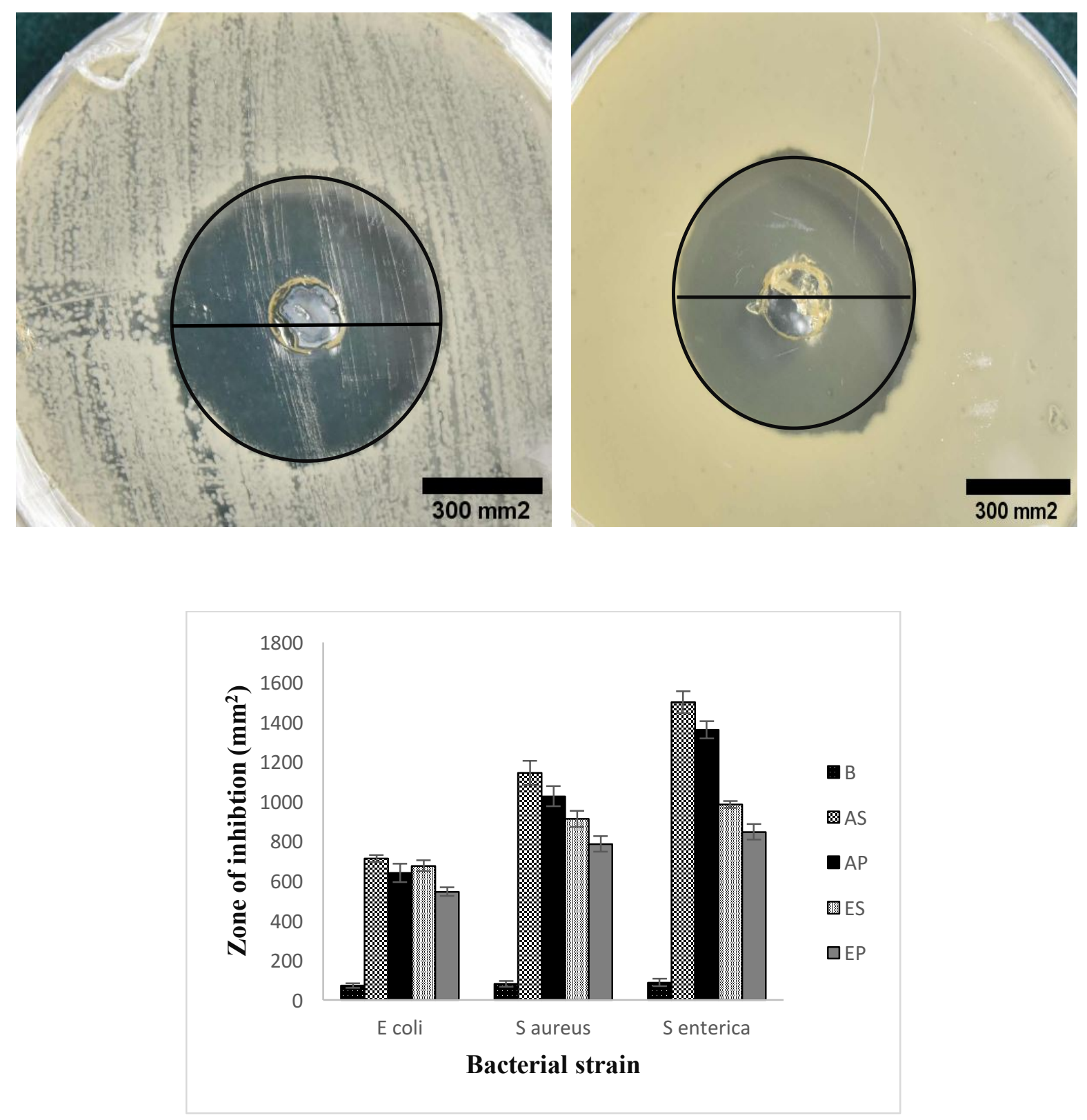
Fig. 7. Representative inhibitory zone by azithromycin (top left), erythromycin (top right) and bar graph representing zone of inhibition recorded from different formulations against $E$. coli, $S$. aureus and $S$. enterica (bottom)

\subsection{Antibiofilm activity}

After $24 \mathrm{~h}$ of bacterial infestation, the incised skin appeared red and inflamed. Microscopic image of a stained sample from the incised, inoculated skin revealed that the bacterial strain present at the infected wound was S. aureus (Figure 9). These results confirm the development of biofilm at the site of injury. Sample from uninfected skin did not depict any bacterial growth after incubation for 24 hours.
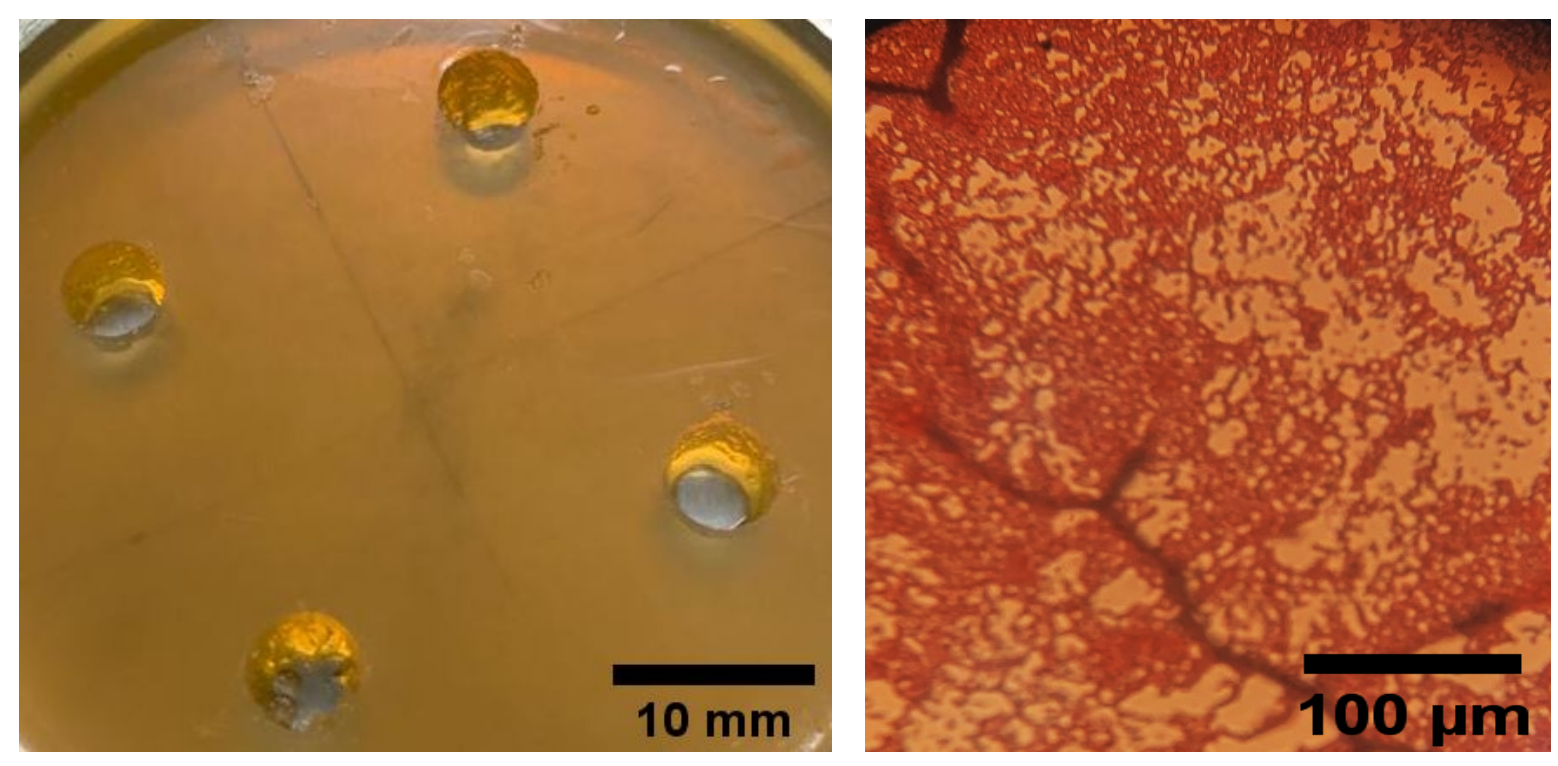

Fig. 8. Sample obtained from non-infected wound representing absence of bacterial growth in agar medium (left) and microscopic image of $S$. aureus isolated from infected wound (right)

Photographic images of the wound, recorded on daily basis, are described in table 3 . It is evident that swelling/redness and microbial activity of biofilm was persistent during the first two days of treatment, maximum on second day. However, on the third day there was an abatement in the swelling and bacterial load was also reduced. By the fourth day, no visible swelling/redness was evident. Furthermore, the results of a swab test, performed to determine the presence of bacteria, were negative. Results confirmed antibiofilm action of prepared patches as, by the fifth day, there was complete wound healing and eradication of $S$. aureus biofilm (Table 2).

Table 2: Photographic images of the wound following treatment with azithromycin and erythromycin loaded patch 


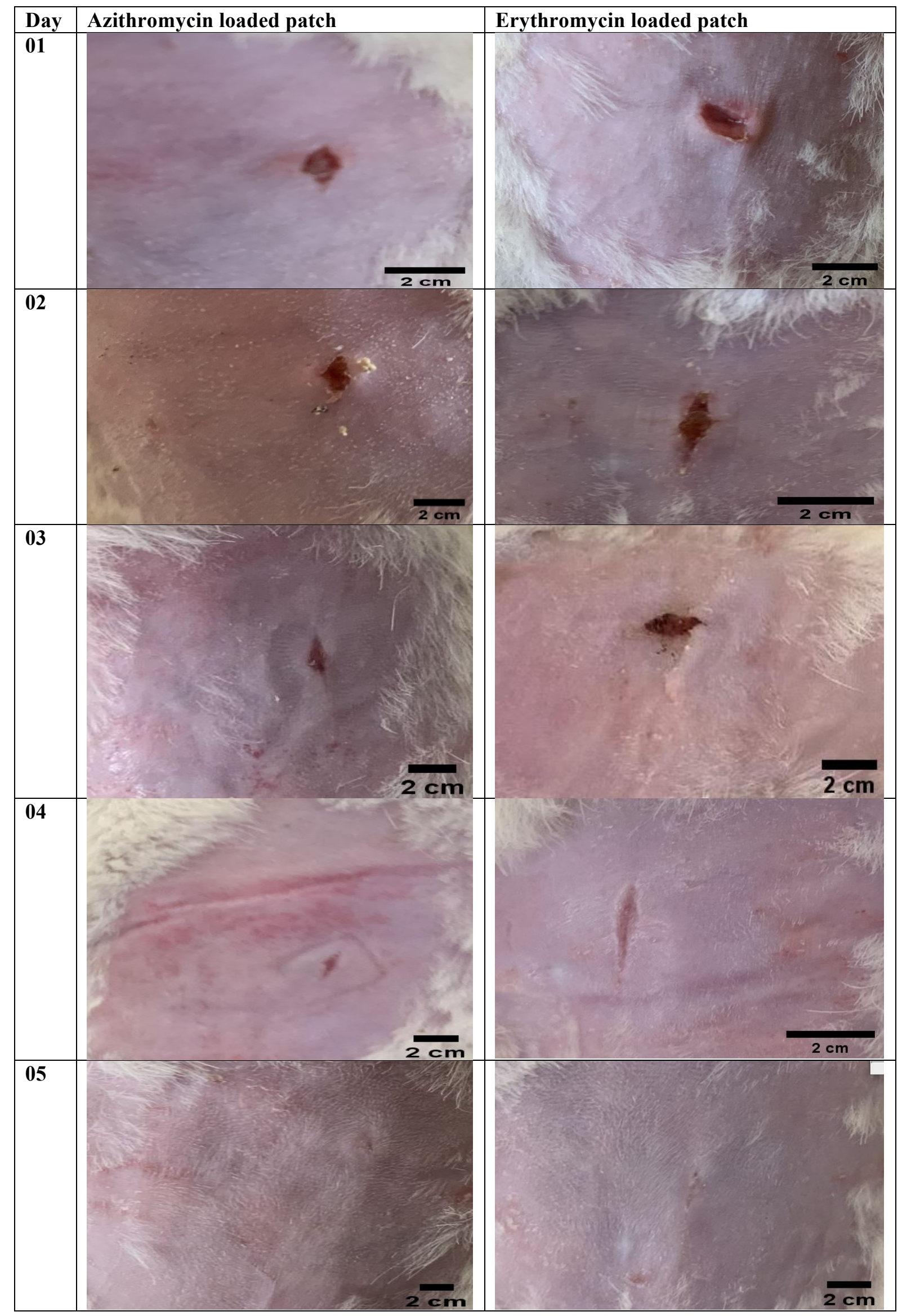




\subsection{Histological examination}

Histological examination of the macrolide treated, incised and infected wounds, is shown in figure 10A. After 5 days of treatment with azithromycin, the skin tissues had healed, resulting in the development of a well-defined epidermis, dermis and hypodermis. Furthermore, the anatomical structures such as veins, hair follicles, sebaceous glands and connective tissues could also be identified.

The erythromycin treated skin samples also developed epidermis, dermis, hair follicles and a vascular structure (figure 10B). However, some structural entities are not as completely developed as observed with the azithromycin treatment. A histological sample of normal skin was included as a ready reference (figure 10C). The incised infected skin, treated with blank MNs, was subject to superficial healing, meanwhile the dermis and hypodermis remained underdeveloped over the same period (figure 10D). From the above results it was concluded that the azithromycin treatment was more efficient in the eradication of $S$. aureus infections and results in faster healing as opposed to erythromycin or blank MN patch. 

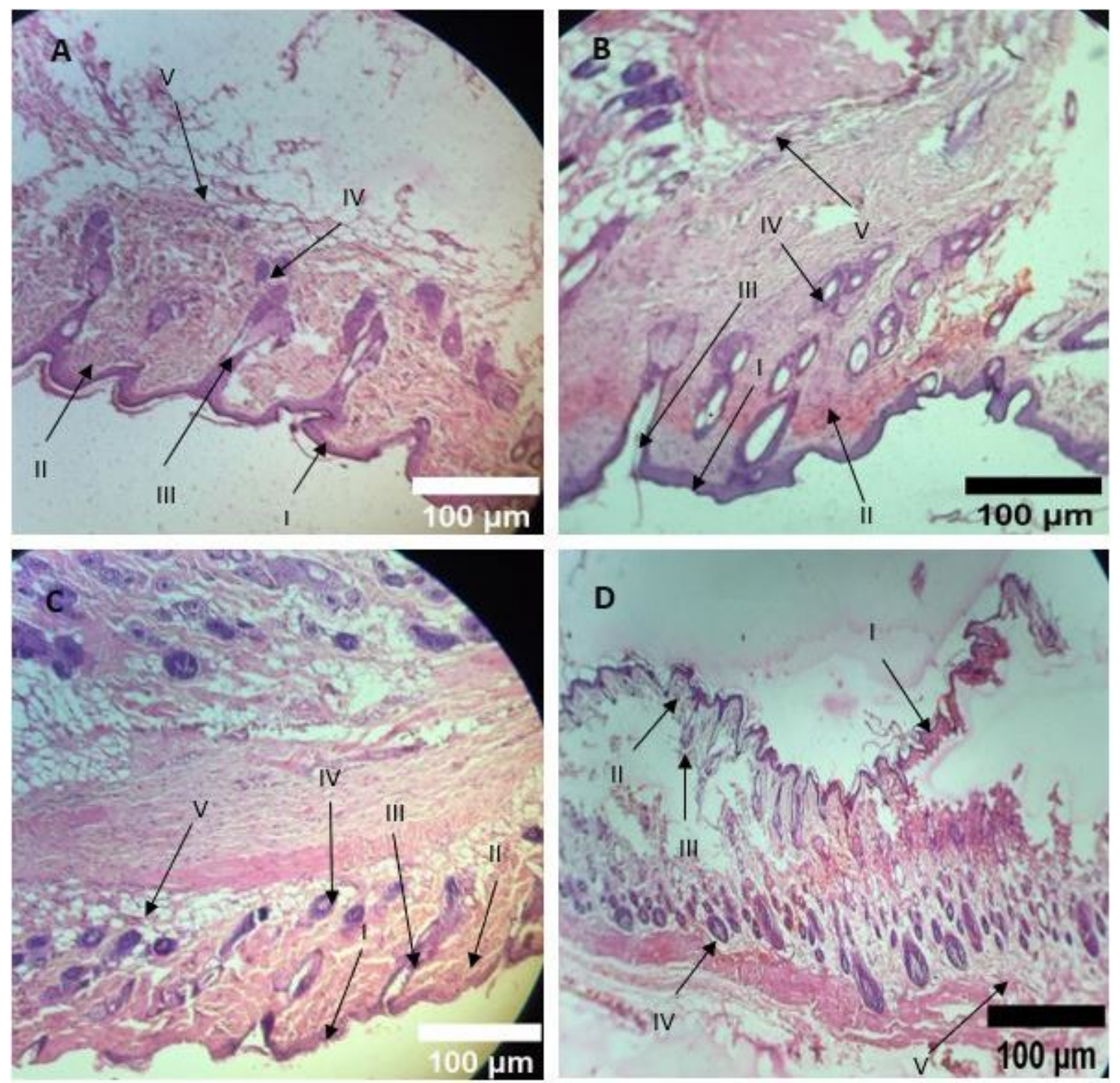

Fig. 9. Histological examination of skin samples A) Azithromycin treated skin, B) Erythromycin treated skin C) normal Skin D) incised skin treatment with blank MN patch (I-Epidermis, IIdermis, III-Hair Follicle, IV-Vein, V-Connective tissue)

\subsection{Discussion}

Wound healing is a complex process involving different physiological factors which act in a synchronous manner to repair skin damage. Skin wounds are at a higher risk of harbouring microbial infections. Frequently, the bacterial strains from the normal flora enters the site of injury and nourish on the moist, profuse tissues. Continuous colonization of the wound area results in biofilms, which can overcome the immune responses and protract the tissue injury. Biofilms are likely to develop on the surface as well as in deeper layers of a majority of chronic wounds $(34,35)$. Due to this reason, the skin healing of infected wounds is delayed, which adds to the burden of disease. Sometimes, subcutaneous tissue injuries results in hematomas 
vulnerable to infections which are difficult to treat (36). Conventional formulation approaches such as ointments, are less efficient in delivering antibiotics to deeper areas of the skin, while oral administration requires higher doses to achieve therapeutic levels at the site of action. To circumvent these challenges, several advanced delivery systems such as smart automated bandages, nanoparticles and iontophoresis etc., have been developed to provide wound specific drug delivery. These approaches promise an optimum therapeutic effect with a relatively lower dose $(37,38)$. MN patch, an advanced delivery system, can efficiently deliver relatively higher drug concentrations to microbes residing inside the deeper layers of skin.

In this study, erythromycin and azithromycin loaded MN patches were successfully fabricated with a polymeric blend comprising of HA and PVP using a vacuum micromolding technique. The biocompatible, biodegradable, bio adhesive and water absorbent nature of the polymers is well known. The formulation constituents are labeled as "generally regarded as safe" (GRAS). They can easily be disposed off by incineration. The disposal process is less energy exhaustive than metals which is adaptable at resource poor settings. Different features of the MN patch, such as morphology of the microprojections, folding endurance $(>100)$ and piercability in parafilm highlight its potential usefulness in the tailored skin invasion.

The results of thermal analysis revealed the thermal stability of all formulation components, as well as, prepared blank patches and drug loaded patches. Absence of distinctive melting peaks of erythromycin and azithromycin in the DSC scan of prepared patches suggested that the drug substances transformed into a more soluble amorphous state in the water-soluble polymer matrix. This phenomenon is envisioned to prompt the drug diffusion into the site of injury. A faster in vitro drug release i.e. $\sim 90 \%$ for erythromycin and $65 \%$ for azithromycin, was observed during the first 30 minutes due to amorphization of the drug and within the hydrophilic polymer PVP. Improvement of dissolution rate of olanzapine following its transition to amorphous form within hydrophilic polymeric matrix (i.e. PVP) has been reported in literature (39-41). This is beneficial as it allows a faster drug delivery at the site of injury. The azithromycin loaded patch showed superior activity (in terms of zone of inhibition) against E. coli, S. aureus and $S$. enterica in comparison to the erythromycin patch. Likewise, the azithromycin patches were more effective in controlling the bacterial biofilm. Histological examination of the skin specimen treated with azithromycin patch after 5 days of treatment, suggested a rapid healing of the wound, coupled with cell maturation (i.e. appearance of definitive cellular structures and connective tissue) as opposed to erythromycin. The superior antibacterial activity of 
azithromycin is due to its higher tissue distribution, cellular concentration, prolonged half-life and higher antibacterial potency $(42,43)$.

\section{Conclusion}

It is concluded that macrolide loaded microneedle patches, of acceptable physical attributes, can be prepared using hyaluronic acid, polyvinyl pyrollidone and sorbitol. The antibacterial activity was retained in the course formulation routine. Use of azithromycin loaded microneedle patches in the eradication of Staphylococcus aureus biofilms is more beneficial in the management of an infected wound than that of erythromycin. Nonetheless, all developed MNs patches exhibited enhanced wound healing and anti-bacterial effect. Our developed method and strategy could be utilised for a wide range of drugs and therapeutics where a synergistic effect of active wound healing and antibacterial efficiency is necessary.

\section{Conflict of Interest}

The authors have no conflict of interests.

\section{Acknowledgement}

The authors acknowledge the financial support provided by Higher Education Commission of Pakistan under National Research Program for Universities (NRPU) vide No: 7401/Punjab/NRPU/R\&D/HEC/2017.

\section{References}

1. Ahmad Z, Stride E, Edirisinghe M. Novel preparation of transdermal drug-delivery patches and functional wound healing materials. J Drug Target. 2009;17(9):724-729.

2. Khan H, Mehta P, Msallam H, Armitage D, Ahmad Z. Smart microneedle coatings for controlled delivery and biomedical analysis. J Drug Target. 2014;22(9):790-795.

3. Percival SL, McCarty SM, Lipsky B. Biofilms and wounds: An overview of the evidence. Adv Wound Care. 2015;4(7):373-381.

4. Ashrafi M, Novak-Frazer L, Bates M, Baguneid M, Alonso-Rasgado T, Xia G, Rautemaa-Richardson R, Bayat A. Validation of biofilm formation on human skin wound models and demonstration of clinically translatable bacteria-specific volatile signatures. Sci Rep. 2018;8(1):1-16.

5. Caffarel-Salvador E, Kearney M-C, Mairs R, Gallo L, Stewart SA, Brady AJ, Donnelly RF. Methylene blue-loaded dissolving microneedles: Potential use in photodynamic antimicrobial chemotherapy of infected wounds. Pharmaceutics. 2015;7(4):397-412.

6. Ali R, Mehta P, Arshad M, Kucuk I, Chang M, Ahmad Z. Transdermal microneedlesA materials perspective. AAPS PharmSciTech. 2020;21(1):12. 
7. Haj-Ahmad R, Khan H, Arshad MS, Rasekh M, Hussain A, Walsh S, Li X, Chang M$\mathrm{W}$, Ahmad Z. Microneedle coating techniques for transdermal drug delivery. Pharmaceutics. 2015;7(4):486-502.

8. Xenikakis I, Tzimtzimis M, Tsongas K, Andreadis D, Demiri E, Tzetzis D, Fatouros DG. Fabrication and finite element analysis of stereolithographic 3D printed microneedles for transdermal delivery of model dyes across human skin in vitro. Eur $\mathrm{J}$ Pharm Sci. 2019;137:104976.

9. Larraneta E, Lutton RE, Woolfson AD, Donnelly RF. Microneedle arrays as transdermal and intradermal drug delivery systems: Materials science, manufacture and commercial development. Mater Sci Eng R Rep. 2016;104:1-32.

10. Ramadon D, Permana AD, Courtenay AJ, McCrudden MT, Tekko IA, McAlister E, Anjani QK, Utomo E, McCarthy HO, Donnelly RF. Development, evaluation and pharmacokinetic assessment of polymeric microarray patches for transdermal delivery of vancomycin hydrochloride. Mol Pharm. 2020.

11. Permana AD, Mir M, Utomo E, Donnelly RF. Bacterially sensitive nanoparticle-based dissolving microneedles of doxycycline for enhanced treatment of bacterial biofilm skin infection: A proof of concept study. Int J Pharm X. 2020;2:100047.

12. Iacob A-T, Drăgan M, Ghețu N, Pieptu D, Vasile C, Buron F, Routier S, Giusca SE, Caruntu I-D, Profire L. Preparation, characterization and wound healing effects of new membranes based on chitosan, hyaluronic acid and arginine derivatives. Polymers. 2018;10(6):607.

13. Price RD, Myers S, Leigh IM, Navsaria HA. The role of hyaluronic acid in wound healing. Am J Clin Dermatol. 2005;6(6):393-402.

14. Rasekh M, Karavasili C, Soong YL, Bouropoulos N, Morris M, Armitage D, Li X, Fatouros DG, Ahmad Z. Electrospun PVP-indomethacin constituents for transdermal dressings and drug delivery devices. Int J Pharm. 2014;473(1-2):95-104.

15. Wang J-C, Zheng H, Chang M-W, Ahmad Z, Li J-S. Preparation of active 3D film patches via aligned fiber electrohydrodynamic (EHD) printing. Sci Rep. 2017;7:43924.

16. Mehta P, Justo L, Walsh S, Arshad MS, Wilson CG, O’Sullivan CK, Moghimi SM, Vizirianakis IS, Avgoustakis K, Fatouros DG, Ahmad Z. New platforms for multifunctional ocular lenses: engineering double-sided functionalized nano-coatings. J Drug Target. 2015;23(4):305-310.

17. Wang L, Chang M-W, Ahmad Z, Zheng H, Li J-S. Mass and controlled fabrication of aligned PVP fibers for matrix type antibiotic drug delivery systems. Chem Eng J. 2017;307:661-669.

18. Nair B. Final report on the safety assessment of polyvinylpyrrolidone (PVP). Int J Toxicol. 1998;17(4_suppl):95-130.

19. $\mathrm{Wu} \mathrm{W}$, Tian H, Xiang A. Influence of polyol plasticizers on the properties of polyvinyl alcohol films fabricated by melt processing. J Polym Environ. 2012;20(1):63-69.

20. Parra-Ruiz J, Vidaillac C, Rybak MJ. Macrolides and staphylococcal biofilms. Rev Esp Quimioter. 2012;25(1).

21. Kanoh S, Rubin BK. Mechanisms of action and clinical application of macrolides as immunomodulatory medications. Clin Microbiol Rev. 2010;23(3):590-615. 
22. Ahmad Z, Vargas-Reus M, Bakhshi R, Ryan F, Ren G, Oktar F, Allaker R. Antimicrobial properties of electrically formed elastomeric polyurethane-copper oxide nanocomposites for medical and dental applications. In. Methods in enzymology: Elsevier; 2012. p. 87-99.

23. Arshad MS, Hassan S, Hussain A, Abbas N, Kucuk I, Nazari K, Ali R, Ramzan S, Alqahtani A, Andriotis EG, Fatouros DG, Chang M-W, Ahmad Z. Improved transdermal delivery of cetirizine hydrochloride using polymeric microneedles. Daru. 2019;27(2):673-681.

24. Arshad MS, Fatima S, Nazari K, Ali R, Farhan M, Muhammad SA, Abbas N, Hussain A, Kucuk I, Chang M-W, Mehta P, Ahmad Z. Engineering and characterisation of BCG-loaded polymeric microneedles. J Drug Target. 2019:1-8.

25. Arshad MS, Zafar S, Zahra AT, Zaman H, Akhtar A, Kucuk I, Farhan M, Ahmad Z. Fabrication and characterization of self-applicating Heparin sodium microneedle patches. J Drug Target. 2020.

26. Larrañeta E, Moore J, Vicente-Pérez EM, González-Vázquez P, Lutton R, Woolfson $\mathrm{AD}$, Donnelly RF. A proposed model membrane and test method for microneedle insertion studies. Int J Pharm. 2014;472(1-2):65-73.

27. Tepe JB, St. John C. Determination of erythromycin by ultraviolet spectrophotometry. Anal Chem. 1955;27(5):744-746.

28. Suma B, Thachemperil JM, Venkataramana C. Spectrophotometric method development and validation of azithromycin in tablet formulation. J Dent Orofac Res. 2018;14(1):23-27.

29. Kafedjiiski K, Jetti RK, Föger F, Hoyer H, Werle M, Hoffer M, Bernkop-Schnürch A. Synthesis and in vitro evaluation of thiolated hyaluronic acid for mucoadhesive drug delivery. Int J Pharm. 2007;343(1-2):48-58.

30. Saroj A, Singh R, Chandra S. Studies on polymer electrolyte poly (vinyl) pyrrolidone (PVP) complexed with ionic liquid: Effect of complexation on thermal stability, conductivity and relaxation behaviour. Mater Sci Eng B. 2013;178(4):231-238.

31. Pignatello R, Mangiafico A, Ruozi B, Puglisi G, Furneri PM. Amphiphilic erythromycin-lipoamino acid ion pairs: Characterization and in vitro microbiological evaluation. AAPS PharmSciTech. 2011;12(2):468-475.

32. Chen Q, Yin C, Ma J, Tu J, Shen Y. Preparation and evaluation of topically applied azithromycin based on sodium hyaluronate in treatment of conjunctivitis. Pharmaceutics. 2019;11(4):183.

33. Loría-Bastarrachea M, Herrera-Kao W, Cauich-Rodríguez J, Cervantes-Uc J, VázquezTorres H, Ávila-Ortega A. A TG/FTIR study on the thermal degradation of poly (vinyl pyrrolidone). J Therm Anal Calorim. 2011;104(2):737-742.

34. Lindholm C, Searle R. Wound management for the 21st century: Combining effectiveness and efficiency. Int Wound J. 2016;13:5-15.

35. Schultz G, Bjarnsholt T, James GA, Leaper DJ, McBain AJ, Malone M, Stoodley P, Swanson T, Tachi M, Wolcott RD. Consensus guidelines for the identification and treatment of biofilms in chronic nonhealing wounds. Wound Repair Regen. 2017;25(5):744-757. 
36. Hashemi K, Donaldson L, Freeman J, Sokhi G, Gyde O, Smith H. The use of topical thrombin to reduce wound haematoma in patients receiving low-dose heparin. Curr Med Res Opin. 1981;7(7):458-462.

37. Saghazadeh S, Rinoldi C, Schot M, Kashaf SS, Sharifi F, Jalilian E, Nuutila K, Giatsidis G, Mostafalu P, Derakhshandeh H. Drug delivery systems and materials for wound healing applications. Adv Drug Deliv Rev. 2018;127:138-166.

38. Mir M, Permana AD, Ahmed N, Khan GM, ur Rehman A, Donnelly RF. Enhancement in site-specific delivery of carvacrol for potential treatment of infected wounds using infection responsive nanoparticles loaded into dissolving microneedles: A proof of concept study. Eur J Pharm Biopharm. 2020;147:57-68.

39. da Costa NF, Pinto JF, Fernandes AI. Co-amorphization of olanzapine for solubility enhancement. Ann Med. 2019;51(sup1):87-87.

40. Arshad MS, Smith G, Polygalov E, Ermolina I. Through-vial impedance spectroscopy of critical events during the freezing stage of the lyophilization cycle: The example of the impact of sucrose on the crystallization of mannitol. Eur J Pharm Biopharm. 2014;87(3):598-605.

41. Lee I-C, Wu Y-C, Tsai S-W, Chen C-H, Wu M-H. Fabrication of two-layer dissolving polyvinylpyrrolidone microneedles with different molecular weights for in vivo insulin transdermal delivery. RSC Adv. 2017;7(9):5067-5075.

42. Jelić D, Antolović R. From erythromycin to azithromycin and new potential ribosomebinding antimicrobials. Antibiotics. 2016;5(3):29.

43. McHugh R, Rice A, Sangha N, McCarty M, Utterback R, Rohrback J, Osborne B, Fleischer Jr A, Feldman S. A topical azithromycin preparation for the treatment of acne vulgaris and rosacea. J Dermatolog Treat. 2004;15(5):295-302. 